\title{
Knowledge uptake by technical professionals and decision-makers for developmental water services Part 1: Methodology, knowledge and context
}

\author{
MB van Ryneveld ${ }^{1 *}$ and SL Sproule ${ }^{2}$ \\ ${ }^{1}$ Department of Civil Engineering Science, University of Johannesburg, PO Box 524, Auckland Park, \\ Johannesburg 2006, South Africa \\ 2 St John's College, St Davids Road, Houghton 2198, South Africa
}

\begin{abstract}
While significant knowledge appears to be available on developmental water services (a term for service provision, to meet developmental objectives, with an emphasis on poor communities, in which a range of factors other than purely technical factors are addressed), there appears to be insufficient uptake of this knowledge (meaning the acquisition, comprehension and application in context) by technical professionals and decision-makers responsible for service provision, as evidenced by persistent service delivery backlogs and poor sustainability. This investigation developed and documented an exploratory methodology based primarily on in-depth interviews and a literature review which enabled the collection of evidence and development of a 'first pass' typology of knowledge, context and individual competencies with respect to developmental water services. This paper addresses the aspects of knowledge and context. Individual competencies are addressed in the companion paper (Part 2).

With respect to knowledge, the investigation found that while there is a lot of information readily available in the sector on the provision of water services to meet developmental objectives, what appears to be weak or missing is information on how to apply this information in context. With respect to context, the investigation established a simple preliminary framework which described the combination of political and technical disciplines in a unified approach, and the translation of this into the bureaucracy. On the evidence of the in-depth interviews, the contextual aspects of developmental water services, described by the above framework - and, in particular, the workings of the bureaucracy - would appear to constitute the major challenge facing high-level technical professionals and decision-makers in the provision and sustainability of water services.

More generally, the investigation established that for effective provision of water services within a developmental context, there is a close relationship between the three components of knowledge, context and individual competencies; and that it is difficult to address any one of the three components without reference to the other two.
\end{abstract}

Keywords: knowledge, developmental, water services, decision-makers, technical professionals, context, individual competencies, bureaucracy, interviews

\begin{abstract}
Introduction
Over the past decade or so in South Africa, there has been a fundamental change in the way in which services are provided, from an approach dominated by technical factors to one in which a range of factors other than purely technical factors are addressed. In this new approach, services are provided to meet developmental objectives, with an emphasis on poor communities. In the water field, a suggested term for this new approach is 'developmental water services'. This change has been acknowledged by the South African Water Research Commission (WRC) in its 2002 Knowledge Review, where it observed that '..the sector is in transformation', pointing to a 'shift in paradigm' as the challenges of integrating technical factors with other factors such as business aspects become more established (WRC, 2002). This review went on to indicate that this is a relatively new field (specifically referring to Integrated Urban Water Management) and that human capacity is relatively low. The Development Bank of Southern Africa
\end{abstract}

\footnotetext{
* To whom all correspondence should be addressed.

急 +2711 559 3511; fax: +2711 559 2343; e-mail: markvr@uj.ac.za

Received 17 September 2008; accepted in revised form 15 April 2009.
}

(DBSA) also identified the low human capacity in the sector and indicated that it intended '...to establish a knowledge institution [in the following] year with the aim of unlocking capacity of local municipalities'(Phasiwe, 2003). However, experience with students in several formal tertiary level courses and experience with practitioners in the field suggests that while there is fairly significant knowledge available within the research community on the change 'from technical design to developmental service provision', there appears to be insufficient uptake of this knowledge by technical professionals and decision-makers responsible for service provision (Van Ryneveld and McCutcheon, 1997). Knowledge uptake is defined here as 'the active acquisition of disseminated information, the comprehension of the information and the ability of practitioners to apply the information in the field'. Significant attention in recent years has been paid to the development of new organisational arrangements, policies, legislation and procedures for developmental water services. This exploratory investigation, by contrast, turned the attention to the uptake of knowledge by individual practitioners at the higher levels within the new service provision paradigm.

The investigation focused on the individual, and explored the uptake - meaning the acquisition, comprehension and application in context - of knowledge on developmental water services. Methodology, knowledge and context are addressed 
in this paper. Individual competencies are addressed in the companion paper (Part 2).

\section{Key elements of developmental water services}

Proceeding from the initial definition of 'developmental water services' as 'the provision of water services to meet developmental objectives, with an emphasis on poor communities, in which a range of factors other than purely technical factors are addressed', a key finding of the investigation was the identification of a further major aspect of developmental water services as 'a combination of political and technical disciplines in a unified approach, consisting of:

- Implementation of services on the ground carried out by technical professionals (in different fields such as engineering, health, housing, etc., often arranged institutionally into departments along those lines);

- Decisions, trade-offs and resource allocations (within limited resources, to meet developmental objectives) carried out by politicians;

...and the institutionalisation of this, or translation into the bureaucracy'.

The interface between the individual technical disciplines (which are usually organised in departments, consisting of officials who are generally technical professionals) and the top political decision-making bodies was identified as a critical one. It is at this interface that the most critical communication - and decision-making - happens at local government level, and which has the most far-reaching ramifications in both directions in the organisation: towards the policy side in the one direction; and towards the implementation side in the other direction. Three illustrations of where this fits into the diagram of a typical institution and of key personnel within it are given as follows: A functional illustration of developmental water services, together with the interface as well as the positions of the individuals interviewed within this arrangement is given in Fig. 1 (see section for abbreviations of individuals interviewed). An organisational illustration of this same interface is given later in the paper in Fig. 4, and a more detailed illustration of this interface within a typical departmental hierarchy is given in Fig. 7.

Although this interface has been selected as the focus of this particular investigation, there is in fact a second interface

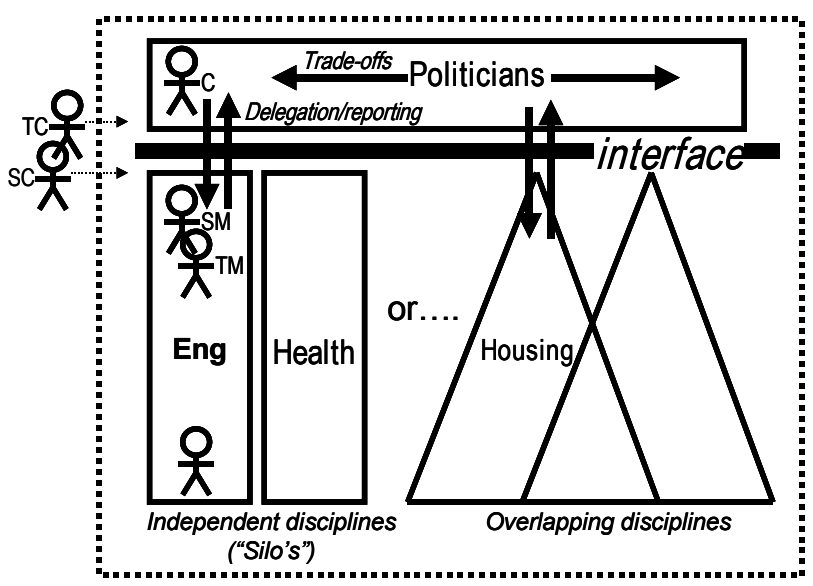

Figure 1

Functional illustration of the context of developmental water services

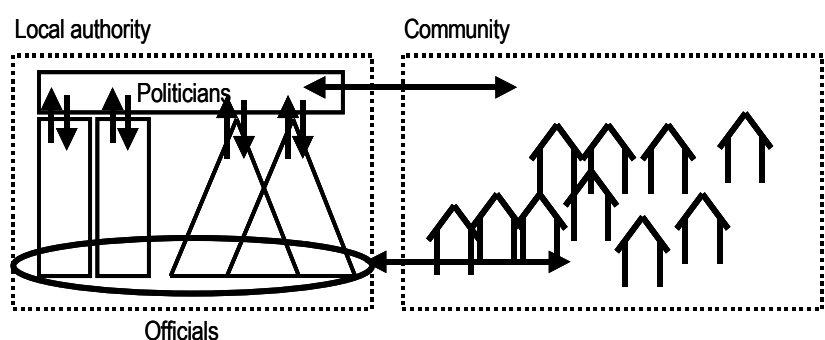

Figure 2

Dual link between local government bureaucracy and community

with two components that was pointed out by the Technical Consultant who was interviewed, which is the interface between the bureaucracy and the community. The interface or link between the bureaucracy and the community is in fact a dual one:

- From the politicians to the community

- From the officials to the community; each of which takes a slightly different form, and is illustrated in Fig. 2.

\section{Methodology}

The sequence in which these components of knowledge, individual competencies and context were explored was as follows:

- The investigation started with a literature review of knowledge on developmental water services.

- This was followed by a literature review of individual competencies (addressed in detail in the companion paper (Part 2)). However, in investigating individual competencies, it was found that one could not make sense of these required individual competencies without also investigating the context in which the individual was operating.

- Investigation of individual competencies and the context in turn led back to a re-examination of the knowledge raising questions as to whether it was appropriate to the context (and to the individual competencies).

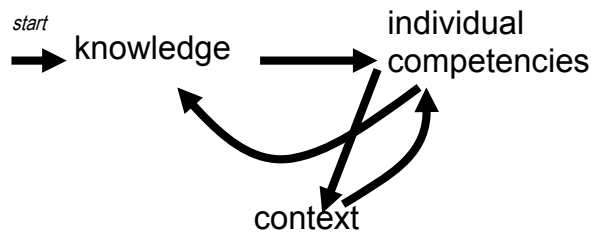

Figure 3

Methodology: Sequence of components explored

The methodology consisted of 2 primary research strategies:

- A review of the literature on the topics of developmental water services provision; and knowledge uptake and related factors, both individually and in combination

- In-Depth case studies in the form of interviews and interactions with 5 technical professionals and high-level decision-makers in the sector in urban/ peri-urban areas.

Two secondary research strategies were employed to support the primary research strategies:

- The in-depth case studies were preceded by observation of typical institutional arrangements and decision-making processes mainly in local government, which provided further insight into the nature of developmental water services, and enabled the researchers to identify and obtain 
access to the context within which individuals were operating, as well as to identify appropriate and representative individuals for the in-depth case studies.

- The in-depth case studies were then followed by an abbreviated postal/telephonic survey of knowledge uptake by technical professionals/decision-makers across the sector, including a further four individuals and consisting of about 10 to 15 questions, to obtain a slightly broader sample of views on the key issues identified within the in-depth case studies. In practice, the abbreviated survey tended towards a number of additional in-depth interviews - albeit abbreviated, and are not discussed further in this paper.

One does not (and cannot really) measure directly what knowledge is taken up by an individual in the sense of what is acquired and comprehended by the brain; nor is it particularly important. Rather, as evidence that knowledge has been taken up, one measures what the individual can do with that knowledge. Knowledge uptake is therefore demonstrated through competence. Knowledge must be visible and used in practice for it to be considered taken up by an individual. Consequently, knowledge uptake is best explored by considering those competencies that are observable in the decisions, discussions and actions of technical professionals and decision-makers. The methodology which has been developed in this study, which made significant use of in-depth case studies in the form of interviews and interactions with individual practitioners, is one which enables those observations to be made.

It needs to be stressed that while this investigation was a comprehensive survey of knowledge, individual competencies and context for developmental water services, it has simply developed:

- An exploratory methodology (described in this section);

- 'First pass' typology of knowledge, individual competencies and context (see companion paper (Part 2) for typology of individual competencies);

It did not provide detailed insight into the extent or severity of the characteristics identified (i.e. how widespread they were, or how severe they were). The number of interviews conducted ( 5 in-depth interviews, followed by a further 4 abbreviated postal/ telephonic surveys/interviews), represents too small a sample to assess either the extent or severity of the characteristics identified. The investigation did, however, translate the findings of this exploratory study into 2 questionnaires (used in the abbreviated postal/telephonic survey of knowledge uptake by technical professionals/decision-makers across the sector, described above as one of the secondary research strategies; included in the original research report). These questionnaires could be used on a larger sample in further research to ascertain the extent and severity of the characteristics identified.

The emphasis of this exploratory investigation was on taking a fresh look at a long-standing and intractable problem, and on developing methodologies to do this. In keeping with this, the key characteristic of the in-depth open-ended interviews (which constituted the primary research strategy) is that within the bounds of the objectives of the study, together with the four main topics, as described in detail below - they are interviewee-directed, and therefore very open-ended. This is critical particularly in the early stages of this exploratory research, because it allows the interviewee to indicate what the problems are and to raise matters that he/she feels are important. Otherwise the researchers are in danger of simply asking the interviewees to comment on predetermined lists, which is self-reinforcing. In contrast with in-depth open-ended interviews, focus groups are not common in this type of research, in that they are too directive. They are commonly used in marketing, to determine who likes a product and who doesn't. There are 2 types of focus groups:

- Groups where the participants don't talk to each other. They are technology-assisted i.e. each participant has a plunger or button by which they register their responses to a range of questions.

- Groups where participants do talk to each other. These groups tend to operate like a jury, where the participants egg one another on, and very often where the view of a dominant personality can hold sway.

In both these cases, the participants are responding to questions posed by the facilitators. The agenda is therefore set by the facilitators, and the interview is not interviewee-directed. Another format that is commonly used in educational research is an ethnographic study, where the researcher walks on the job for an extended time (a week) and observes what is going on. This methodology may be utilised in further research.

\section{Gaining access to the context and to the individuals}

Gaining access to individuals for in-depth interview purposes was a progression rather than an event, which started long before any formal application for an interview, as follows:

- Initial contact or pre-approach phase: Before even making the approach, there needed to be some form of contact with the organisation - and, if possible, with the individual which required involvement by the researchers in a range of initiatives at a relatively high level over an extended period of time. Without this involvement, it would have been difficult to obtain access to the individuals for the interviews.

- Approach and appointment phase: Even following the initial contact or pre-approach phase, it did not generally prove possible to dive straight into a request for an in-depth interview. Such an approach needed to be made in 2 stages:

- Verbal - or brief written request accompanied by brief supporting documentation - for an initial exploratory interview of 20 to $30 \mathrm{~min}$;

- If that was successful, then a more detailed request for an in-depth interview of $1 \mathrm{~h}$ or $1.5 \mathrm{~h}$, with further supporting documentation

While we did settle on certain broad procedures, the methodology - and interview methodology - was constantly being developed and refined/adjusted through all the preparatory stages, and even through the interviews themselves. All contact, whether it translated into in-depth interviews or not, assisted in the development of the methodology, by allowing us to make the transition from passive observation to active interaction with individuals on our terms within the scope of the investigation.

We encountered something of a 'chicken-and-egg' situation regarding the compilation of the interview questions: We really needed the opportunity to talk to people in an exploratory manner in order to see what topics we could explore in the interviews, and what the critical issues were; but we were in several instances asked to state exactly which questions we wanted to ask before we would be granted an interview.

It took considerable effort and patience to convert an initial contact into an in-depth interview, and overall, within the broad time frames of the research project, time spent gaining 
access to the context and to the individuals was substantial. Interestingly, those individuals who asked a large number of questions and required a large amount of explanatory information were those who in the end did not grant interviews. Those who granted interviews tended to do so with fewer questions asked. Some at high levels granted interviews readily; others had problems to fit us into their schedules; some made alternative arrangements for deputies to grant us interviews.

The individuals interviewed were representative of a spectrum of positions across the interface between technical professionals and high-level decision-makers. And although representative of that spectrum, they did in fact come from a number of different organisations. For the record, there was a mix of race and gender; however to disclose further details may compromise the identities of the individuals. The five individuals interviewed for the in-depth case studies were as follows (see Fig. 1 for the position of these individuals within the functional arrangements; abbreviations in the figure, e.g. $\mathrm{C}=$ Councillor, refer to individuals interviewed):

- Councillor (political) (C)

- Senior Manager (managerial) (SM)

- Technical Manager (managerial/technical) (TM)

- Social consultant (managerial/social) (SC)

- Technical consultant (managerial/technical) (TC)

\section{In-depth interview methodology}

In essence, the objective of the study was to understand better what the problems were confronting technical professionals and high-level decision-makers, and to make connections - if there were any to be made - between the problem in the global sense (i.e. we have made good progress in terms of policy etc.; we know quite a lot about water services; why then are we not performing better in terms of delivery, sustainability, etc.?) and the specifics of the problems that confronted the individuals. Furthermore, we were endeavouring to do it in such a manner as to get at the problem without 'getting at' the individual. By the time we started the in-depth interviews, we had adopted a parallel approach with respect to the objectives of the study, i.e. why we were there and what we wanted to get out of it. We gave a brief statement of:

- The problem in the global sense: i.e. 'we have made good progress in terms of policy etc.; we know quite a lot about water services; why then are we not performing better in terms of delivery, sustainability, etc.?'

- The scope of the project: focus on knowledge uptake including application and use; alternatively, 'how learning happens in practice'; focus on the individual not the organisation; technical professionals and decision-makers at the higher levels

- A summary of early findings primarily of the two literature reviews

- Some ground rules: confidentiality, i.e. we were not wanting to identify either specific organisations or specific individuals.

These matters were set out in detail in the supporting documentation which accompanied the request for interviews. Secondly, we identified 4 main topics for investigation:

- The roles and tasks that technical professionals and highlevel decision-makers actually perform

- Characterisation of the decision-making process, including what decisions actually get taken, and the relationship of decision-making to detailed implementation
- Characterisation of the individuals currently performing these tasks, in terms of competencies and other characteristics that may affect the process e.g. learning style

- Characterisation of disciplines operating at this level (primarily the distinction between technical professionals nominally engineers - and politicians)

This focus did change somewhat as the interviews progressed and as topics started to emerge. We attempted to do 2 things: to direct the interview according to the particular strengths and possible contribution of the individual; and to cross-check topics that may have arisen in other interviews.

The interview took the form of a dialogue with questions tending to follow on from one another in a 'thread', so as to retain the flow of the dialogue. It did not consist simply of a list of predetermined questions. In practice, therefore, one had to think on one's feet, leaving topics out where the conversation took a different but useful direction, and introducing our own topics where the discussion moved within range. Our impression was that the interviewees were more apprehensive at the start of the interview, but eased up as the interview progressed. We were wanting to give the interviewees an opportunity to talk about the good things rather than the bad things. It was therefore not our intention to ask controversial questions. We did get a sense that having a structured opportunity to give an account of what they did was not something that the interviewees were accustomed to.

The format that emerged as being manageable/appropriate within the time available, which was more of a framework than a detailed format, and that we settled into, was as follows:

- Brief introduction to the research project (and preliminary findings of the literature reviews)

- Opening question: 'What does your day-to-day job entail?'

- A variety of topics that flowed from that

- Formal questionnaire on the competency table, or 'tick-box time'

- Brief questions giving pointers on learning style

- Brief post-interview discussion, which often included a couple of extremely useful informal anecdotes and comments

We as interviewers were not interested in particular individuals. Questions were phrased as much as possible in generic terms, so that interviewees' answers referred to groups of several individuals and from different organisations and different spheres of government. While the views of individuals were obviously coloured by their experience of those with whom they worked, their experience - and particularly those of the support consultants - tended to be broader than any single organisation. While the politicians/officials and technical/nontechnical personnel expressed views of the other group, it was particularly useful to have the views of support consultants who could express opinions of both groups from a third party perspective (see Fig. 1 for the positions and perspectives of the various interviewees).

Interviews lasted $2 \mathrm{~h}$ each on average, ranging between about $1.75 \mathrm{~h}$ and $2.25 \mathrm{~h}$. These interview durations in turn translated into transcribed lengths of between about 10000 and 15000 words each.

\section{Analysis of the in-depth interviews and themes that emerged}

It was surprising how difficult it was to read the transcribed text. It certainly provides very clear evidence that the 
structure and style of verbal communication is quite different from that of written communication. Interviews that seemed perfectly coherent when spoken suddenly seemed to come across as Pidgin English when transcribed. Two different approaches were used to extract key findings from the in-depth interviews:

- Investigation of the context required a search for a pattern, not knowing initially what one was searching for

- With respect to the individual competencies, an initial framework compiled from the literature provided a good indication from the outset of what to search for; however, the key finding was what was missing from the initial framework, rather than what was there at the outset.

Both approaches are described in more detail below.

With respect to the context, it was virtually impossible to recognise any pattern in the raw interview transcriptions. They had to be reduced to something more manageable, which was done as follows:

- List the thread of the discussion, by writing out the questions asked and prompting comments inserted, while ignoring for the moment the replies. That reduced each interview to about 20 questions/topics.

- Extract key quotes from the interview transcripts, edit them - paraphrasing where the quotes were difficult to read - and reference them so that one could refer back to the original transcript.

Once that was done, the task was to read them over and over again, giving them short headings, rearranging them and looking for patterns. Finally, patterns did emerge, which were articulated and then checked against the transcripts again. Very significantly, we found again and again that, in terms of the context, the working of all facets of the bureaucracy was by far the major topic that was brought up. What was also particularly interesting was that the topic emerged from the detail. In other words, we discussed the specifics of what the problems were, and recorded those. It was only when we analysed those carefully and looked for patterns that the topic started to emerge. It was not something that was immediately recognisable from the detail. It was the single overarching topic emerging from the in-depth interviews that appeared to link the problem in the global sense (i.e. good progress in terms of policy and knowledge about water services, but less satisfactory delivery and sustainability) to the specifics of the problems that confronted the individuals.

With respect to the individual competencies, an initial framework in the form of a draft competency table compiled from the literature provided a sound starting point. Key quotes from the in-depth interviews were coded and classified according to the draft competency table, and integrated with the literature in a draft report. Repeated interrogation of the in-depth interview text, the draft competency table and the literature produced the final competency table.

\section{Knowledge: Review of the literature on developmental water services}

One of the first tasks of the research was to carry out a brief review of the literature on developmental water services, which was carried out under 5 headings:

- Curricula of tertiary level institutions

- Information and training materials

- Booklists and bibliographies
- Organisations and websites

- SA government policies and related documentation

The review appeared to confirm that there was fairly substantial and accessible (i.e. available on the Internet) information available on the topic.

Questions initially raised by the researchers as to why uptake of this knowledge had not taken place as well as one might have liked - as evidenced by service backlogs and poor sustainability - focused first on the identification and acquisition of the knowledge, including topics such as: access to the information, format of the information, cross-disciplinary nature of the information and workplace obstacles to sourcing the information. However, the investigation soon moved to the application of the knowledge within the required context, and to the appropriateness of the information to developmental water services. Something appeared to be missing. What it was, however, was not initially clear.

A first indication of what may be missing is articulated by Wooldridge and Cranko (1997: p.340), who suggest that '...the state's core mission [is] to represent society's interests through the delivery of goods and services in a context of managing conflicting interests. The management of conflicting interests is not a neutral exercise, rather it is rooted in the promotion of the interests and values that constitute the particular mandate of the elected representatives in government.'[bold type added]. What is suggested is that the political discipline (which at the highest level in local government takes the form of the Mayoral Committee) plays the specific role in strategic decision-making of allocating resources and making trade-offs between the different technical disciplines - and appears to be what is missing from the conventional literature. This appears to be a reflection of the highly politicised nature of service provision in South Africa.

Nosich introduces the notion of a discipline. What is suggested here is that developmental water services is an agglomeration of a number of different disciplines. Each of these disciplines, e.g. engineering, environment, health, etc., operates to a greater or lesser degree as an independent 'silo'. Each of these disciplines operates with its own logic (Nosich, 2001: p.53). As Nosich describes it: 'There is, unfortunately, a common impression that a field is essentially a body of information....Practitioners in a field - at whatever level of education - do not simply possess information. Rather, they know how to use that information as well as the concepts that structure it.... A field or discipline embodies a way of thinking about the world, a way of solving problems and answering questions.... A good way to describe practitioners is to say that they have ownership of the logic of the field.' Nosich (2001: p.55) goes on to suggest that a way of getting at the logic of a field is by '... learning the vocabulary of the field, grasping the fundamental and powerful concepts of a field, and thinking in terms of the central questions of a field'.

Also following a 'critical thinking' approach, Elder and Paul (2002, p.8) give further insight into the difference between the technical and the political disciplines within developmental water services by introducing the notion of different types of question. While this requires further investigation in practice, it appears probable that the technical and political disciplines will tend to be characterised by different types of question: 'In approaching a question, it is useful to figure out what type it is. Is it a question with one definitive answer? Is it a question that calls for a subjective choice? Or does the question require us to consider competing answers?': 
- Questions of procedure (settled by facts, by definition, or both) i.e. 'one system'

- Questions of preference (as many answers as there are different human preferences) i.e. 'no system'

- Questions of judgement (questions requiring reasoning, but with more than one arguable answer) i.e. 'conflicting systems'

Technical considerations are generally 'one system' questions. Political considerations are generally 'conflicting systems' questions.

Combining the three ideas of trade-offs; disciplines; and different types of question... yields a more accurate description of the concept of developmental water services within the local authority consisting of an agglomeration of different disciplines - both political and technical; with the technical disciplines focusing on implementation, and the political discipline focusing on making decisions and trade-offs and allocating resources between the different technical disciplines to achieve policy objectives.

Disciplines alone, however, do not give the complete picture. What makes it much more significant is that the arrangements are strictly formalised within the workings of the bureaucracy. Wooldridge and Cranko (1997: p. 338) go on further to describe the workings of bureaucracies like local government from the policy end towards the implementation end as follows: 'Rational bureaucratic administrations close off the space for flexibility and innovation within administrations, through the use of regulatory mechanisms. At the micro-level officials and front-line workers are tied down by narrowly defined job descriptions, and interactions between politicians, officials, management, and front-line workers are regulated by the rigid hierarchy, staff codes and regulations. Similarly, at the macro-level the ultra vires principle limits the scope of what can be done, and therefore the administration may only act in terms of the confines of the competencies as described by law.'

\section{Context: Observing the institutional arrangements and decision-making process}

As described in the Methodology section, the in-depth case studies were preceded by observation of typical institutional arrangements and decision-making processes - mainly in local government, which provided further insight into the nature of developmental water services; and enabled the researchers to identify and obtain access to the context within which individuals were operating, as well as to appropriate and representative individuals for the in-depth case studies.

The case of the City of Johannesburg is used by way of illustration. It should be stressed at this point that while the City of Johannesburg is used as illustrative of typical institutional arrangements and decision-making processes, the individuals interviewed in the in-depth case studies in fact came from a range of organisations, and no link between the individuals interviewed and the City of Johannesburg should therefore be inferred. The institutional arrangements for water services in the City of Johannesburg are described in Fig. 4 as illustrative of a local government bureaucracy. While the arrangements are more complex than would be encountered in a typical South African local authority, they do nevertheless provide an illustration of the 'organisational' context of developmental water services in its more complex form. Figure 4 should be compared with Fig. 1, which is an illustration of the 'functional' context of developmental water services'. Figures 1,4 and 7 should be compared with one another for an

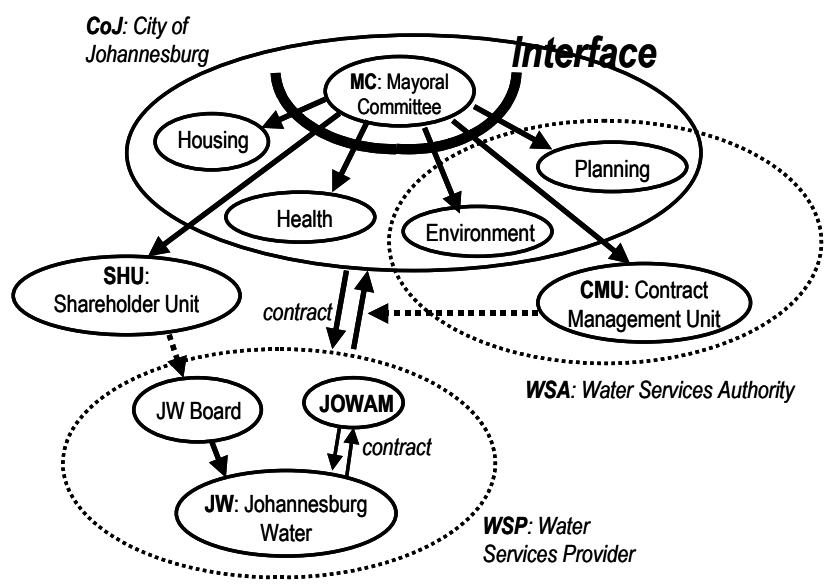

Figure 4

Institutional arrangements of the City of Johannesburg, illustrative of the organisational context of developmental water services

illustration of the 'interface' between policy/decision-makers and technical professionals.

It should be noted that the governance structures and institutional arrangements of the City of Johannesburg as described here, including the committee structure, contractual arrangements, decision-making model at mayoral level, etc., have all recently undergone a process of review and change, following the elections of March 2006 and the decision of the Board of Johannesburg Water (Pty.) Ltd. on 7 September 2005 not to extend the 5-year management contract of JOWAM when it expires on 30 June 2006 (Johannesburg Water, 2005; Cele, 2006). The arrangements have therefore changed slightly, but have been retained here, noting that they are merely illustrative of a local government bureaucracy (in its more complex form):

The entity termed 'City of Johannesburg' is the core local authority body, consisting of a Mayoral Committee, which is the main decision-making body of the local authority, and to whom a number of departments within the City report, e.g. housing, health, planning, environment etc. The Mayoral Committee is probably the key point of interaction between politicians and technical professionals.

For the provision of water services, the City has chosen to set up a proprietary limited company, Johannesburg Water (JW), in which the City is the full shareholder. All water services-related assets of the City were transferred to Johannesburg Water - as were a large proportion of City personnel involved in water services. The relationship between the City and Johannesburg Water is governed by a Service Delivery Agreement (SDA) or contract. The contract, in turn, is regulated by the Contract Management Unit (CMU) of the City. The Shareholder Unit (SHU) appoints the Johannesburg Water Board and is responsible for ensuring that the City's interests as shareholder in Johannesburg Water are looked after.

While the portfolio of Water Services Authority (WSA) Manager has been assigned to the Executive Director: Development Planning, Transportation and Environment (ED: DPTE), the actual WSA functions are carried out jointly by DPTE and CMU (with certain functions carried out by SHU as well).

In addition to this, Johannesburg Water has entered into a contract with a management contractor, JOWAM, to manage JW and build capacity for a limited period (provisionally for 5 years, from 2001 to early 2006).

From a decision-making point of view, the City of Johannesburg is both big and complex. Although the Mayoral 


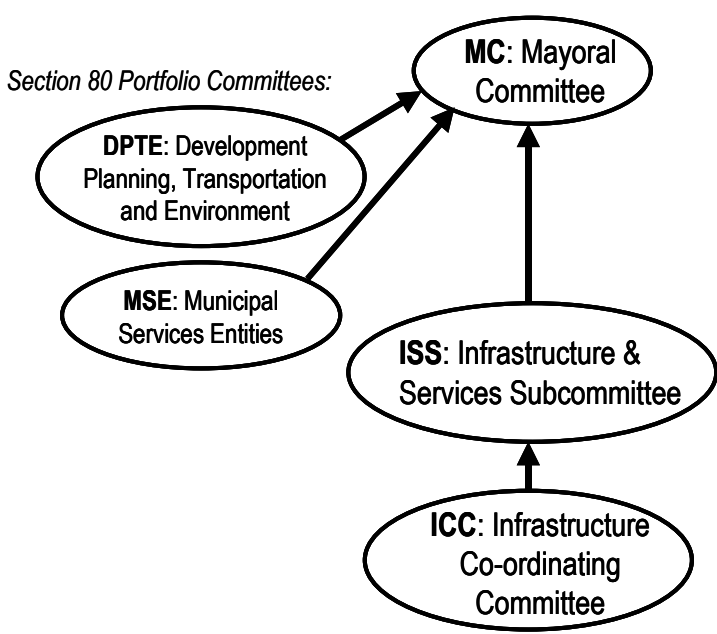

Figure 5

Reporting lines of decision-making committees in the City of Johannesburg

Committee is the primary seat of decision-making, many of the decisions are confined to at least some degree by the prior contractual arrangements between the various entities in the City. The City can, of course, choose to override these contractual agreements. However, there is invariably a financial cost attached to such an action.

Other than to focus attention on the Mayoral Committee (and to a lesser degree, on other policy-setting bodies or instruments), the institutional arrangements do not really shed much light on the actual decision-making process. That is better described by the reporting lines of the various committees up to final decision-making at the Mayoral Committee, which are presented diagrammatically in Fig. 5 with explanation following.

The Infrastructure Co-Ordinating Committee (ICC) is the most senior committee made up of officials (as distinct from politicians) that prioritises and co-ordinates any infrastructural development initiatives in the City from the perspective of officials (which include most of the infrastructure-related technical professionals in the City). City departments such as planning and housing are represented on this committee, as are the utilities such as Johannesburg Water.

Once an agreed view of officials has been obtained from the ICC, a report is submitted to the Infrastructure and Services Subcommittee (ISS), with accompanying presentation. This committee is attended by both officials and politicians. It is a first opportunity for the politicians to have sight of any issues before it gets to the Mayoral Committee. Once a report has been passed by the ISS, it tends to have a smooth ride through Mayoral Committee.

The role of the Section 80 Committees is slightly different. They are portfolio committees, attended by councillors from the full spectrum of political parties. Discussion therefore appears to be characterised more by party-political sensitivities than the ISS.

The Mayoral Committee - as indicated earlier - is the top decision-making body of the City. The committee usually has a substantial agenda. Documentation is substantial (a 'telephone directory-sized' pile of reports); and time for presentation and discussion is limited. Time for presentation and discussion is relatively short for all committees: typically 15 to $20 \mathrm{~min}$ of presentation, followed by 10 to $15 \mathrm{~min}$ of discussion. Usually the more senior the committee, the tighter the time, and the more diverse is the audience.
The major conclusion from observing typical institutional arrangements and decision-making processes is the critical importance of the Mayoral Committee/Executive Mayor in decision-making for developmental water services. Although the specific institutional arrangements of the City of Johannesburg - specifically the setting up of a separate WSP in the form of Johannesburg Water - are somewhat unusual by South African practice, the key position of the Mayoral Committee/ Executive Mayor is typical of other local authority arrangements.

\section{Context: Detailed analysis of in-depth interviews}

In analysing the comments from the in-depth interviews from the perspective of the context within which individuals are operating, the three components of developmental water services identified earlier in the study emerged as overwhelmingly dominant, namely:

- Implementation of services on the ground carried out by technical professionals (in different fields such as engineering, health, housing, etc., often arranged institutionally into departments along those lines)

- Trade-offs and resource allocations carried out by politicians

- The institutionalisation of this, or translation into the bureaucracy

Virtually all comments from the in-depth interviews relating to the context within which individuals were operating could be grouped into two (or possibly three) main categories:

- Interactions across the interface between politicians and officials/technical professionals - nominally 'down the hierarchy';

- The making of trade-offs and key decisions of principle, requiring prioritisation between different projects and different departments - nominally 'across the hierarchy'.

...and a third category of characteristics which applied to both categories:

- Characteristics and requirements (applying both down and across the hierarchy)

One further minor category of 'external requirements/constraints' could be added, but is really too small to be significant.

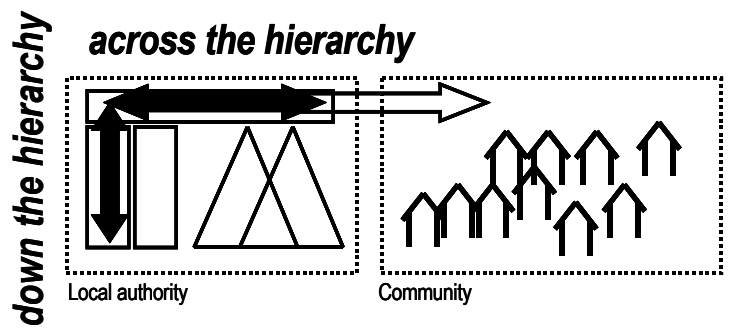

Figure 6

Diagrammatic representation of 'down' and 'across' the hierarchy

In each case, comments related to the particular function as well as to the institutionalisation of these or translation into the bureaucracy. The above diagram depicts the local authority - consisting of officials and politicians within a hierarchy - interacting with the community in the provision of services, indicating the interactions 'down and across the hierarchy'. 


\section{Category\#1: Interactions across the interface between politicians and officials/technical professionals - nominally 'down the hierarchy' (from politicians to officials)}

Within Category\#1, there appeared to be 2 main themes or subgroupings:

- Translation or conversion from: policy ....to delivery; general ....to specific; abstract ....to concrete; purpose ....to technique (see quote by Benson, 2006, below); and nontechnical.... to technical

- The bureaucratic aspect of this translation, namely delegation of authority, and reporting in reverse; allocation of resources, specifically budget allocations, and reporting on budget expenditure in reverse

With respect to the translation from purpose to technique, Benson (2006) comments as follows: 'For many years now, there has been, at every level of society, a growing gap between the techniques of disciplines and the purposes of disciplines. We have been learning how to do particular things, in other words, but not what they are for'.

Conversion from policy to delivery and abstract to concrete was expressed by the Councillor:

"...this is an attempt from the perspective of [particular local authority] to translate this constitutional obligation into reality." - Councillor

A similar comment was repeated by the Social Consultant: '...politicians...are supposed to see that the Constitution is translated into tangible things.' - Social Consultant

A number of practical examples, both abstract and concrete, faced by the local authority - as well as the difficulty of resolving them and translating from general-to-specific or abstractto-concrete and vice versa - were articulated by the Councillor [Summarised/paraphrased in several places]:

- How is 'a household' defined? (Is it defined by an erf? what if there are 5 more shacks at the back of the erf?)

- Is $6000 \mathrm{\ell} /$ household·month sufficient?

- What if you have got a large extended family?

- What if you are using full-flush sanitation (using 10- $15 \ell$ of clean water per flush)?

- These households are generally poor, underemployed or unemployed altogether. 'Until now we have been sustaining this through cross-subsidisation...The reality is that you end up with at least $25 \%$ of your large water users crosssubsidising everybody else. But if you grow the number of dependants, [it] is just not sustainable, so then that remains one of the challenges'.

- Who is poor? Do we use a means test to determine that?

- Sewer blockages, as a result of using newspaper for toilet paper

- The need for educational awareness

Virtually all of the above examples are divergent problems in a technical context. They are policy and planning problems, but are not (in the first instance) spatial planning problems. Nevertheless, if one does not understand the technical implications of these problems, then one is equally in trouble. Many of the problems that now confront a local authority or service provider are planning and technical problems intertwined. In most conventional civil engineering projects, the planning precedes the engineering in a fairly sequential manner. It seems that in services provision, there is a much closer ongoing interaction between the planning and the engineering. The day-to-day issues raised by the Councillor are not resolved once-off before proceeding to service delivery. They arise, unfold and are resolved in the course of a service delivery programme. They have implications for the technical work, but are not generally in themselves problems that can be resolved by technical means - or by technical means alone.

Another example of a practical problem illustrating the difficulty of translating policy into delivery and abstract into concrete was given by the Councillor. It was a case where several hundred people had illegally invaded land, but nevertheless have the right of access to water and sanitation:

'...if you want to be legalistic about it, they are illegal, but that does not take away their right to have access to water and sanitation. ... It is a very complex thing. It's a very practical thing'. - Councillor

The point is made that there is significant complexity in the specifics of these issues as encountered on the ground. One generally tries to deal with the complexity on the ground by making in-principle decisions. But to translate the general into the specific on the ground, and to translate the specifics of what is happening on the ground back into general terms is extremely difficult.

The different responsibilities of technical and non-technical personnel were raised by the Social Consultant, with particular reference to ward councillors:

'You get a sense that they ... have got a grasp of what this project is all about [and] what it is supposed to deliver. In terms of your technicalities you leave that to your engineers or your technical team...They can [take] you to task if you try and give them something that is not in line with what they are supposed to be getting. ... I can tell you they are ...sharp. Where they get that sharpness from, I don't know.' - Social Consultant

What he also points out is that while the ward councillor may not be strong technically, he nevertheless has a good understanding of what he wants - presumably in general terms - and knows when he is not getting it.

Two key procedures are used to work these processes into the bureaucracy. The first is delegation of authority:

'Councils are strong on delegations, and what is delegated from Council level down... There are layers of delegation, and you have to get that right. Any organisation has that and you tend to find that in formal organisations, while everyone says that they all work well - and they all do they end up fighting about those things they haven't clarified. You have to clarify certain matters.' - Senior Manager

Delegation of authority is generally accompanied by reporting back in return on what has been delegated, which has its own difficulties:

'...a lot of time is being sucked away from your job in this kind of organisational bureaucracy. It is dysfunctional reporting. It hasn't been streamlined enough. It hasn't been made simple enough....If you do this stuff, it drives you nuts, like doing ten tax forms simultaneously.' - Senior Manager

Lack of delegation of authority - or politicians trying to micromanage the detailed implementation can also pose difficulties: 
'I think without trying to manage the politicians, they will manage you, and when I say they will manage you, they try and manage your [capital expenditure] programme in a way that has no engineering or service delivery logic. They will basically say 'But why haven't we got more money spent in that area?'. That is the essence of their view of life. '...That ward there, you haven't spent money. Where is the pipe?...' and from that point of view, there hasn't been activity. There hasn't been soil turned. 'So where is someone employed? I haven't been able to cut a ribbon.' etc. You have to try and get them out of that detail.' - Senior Manager

Budget allocations and control of the budget is a critical aspect that accompanies delegation of authority. One of the ways that authority is delegated is in terms of the size of a single order that can be authorised. A fairly long discussion followed with the Technical Manager, explaining the levels of authorisation:

'There is a certain threshold [of the order of R100 000] for a single order, above which an order has to be authorised by the executive. It is unusual for that to be exceeded unless it is a capital expenditure item, or unless it is a large occasional order of a routine item e.g. chemicals.' [Paraphrased:] The point was also made that circumstances do arise where significant over-budget expenditure may be required on a particular item. When that happens, one will have to cut the budget somewhere else and cross-subsidise. One cannot simply overrun the budget. - Technical Manager

The Technical Manager explained the matter further as follows: 'When you don't fundamentally understand how you set up that budget in the first place, when things go wrong and your budgets start overrunning, you are clueless as to what is happening. So that's really important to understand that.' - Technical Manager

The comments are significant from two points of view: Firstly, budgetary control is critical; and secondly, things often don't go exactly as planned, and need adjustment.

\section{Category\#2: The making of trade-offs and key decisions of principle, requiring prioritisation between different projects and different departments - nominally 'across the hierarchy'}

Within Category\#2, there appeared to be three main themes:

- Conflicting objectives

- Trade-offs and prioritisation within limited resources

- Risk and mitigation of risk

The issue of limited resources was well described by the Social Consultant:

'Everyone would want to be in this first-world economy, where if you feel like having five bathrooms you can do that if you can afford to do that, but the limiting factor now is around the resources that you have got, even [if] you have got the facilities within your neighbourhood, because there are issues around the payment for that.' - Social Consultant

Because of limited resources, it is not possible to achieve everything all at once. Prioritisation is obligatory. In several instances (particularly in instances described by the Senior Manager and Technical Consultant) a common feature was that the individual had in the pursuit of their own responsibilities selected particular high-profile initiatives for priority attention, and had then focussed significant effort in these initiatives.

And in prioritising, trade-offs between conflicting objectives are necessary:

'... [the demands] all pull in different directions. Basically, if you wanted more of this [or] these you would have less of these....and that seemed to me a very difficult thing for [the politicians].... It would be a different day of the week and they would be shouting about a different one of these things.' - Senior Manager

The Councillor was very aware of the need for trade-offs and prioritisation within limited resources, using the term 'schizophrenic' to describe the tension between wanting services to be delivered to an acceptable standard on the one hand, and wanting the delivery to be financially sustainable on the other.

On the effectiveness of politicians in making these tradeoffs, the Senior Manager commented as follows:

'Politicians don't understand trade-offs easily. They want it all. They are wonderful people. They want the wife and four girlfriends all at once on the same budget.' - Senior Manager

But the difficulty of doing this was described in some detail by the Councillor. He described the process of establishing a political position and getting community acceptance on a difficult issue, and explained well the difficulty of establishing such a position when views are not uniform:

'Technically the solutions are not difficult, but the issues of getting buy-in, your technical people are not going to do that. You must clear the politics. You deal with the household. After the household is OK, the technical people will do what they do best... You have all these political agendas. So it meant that I had to work through my own [political party] caucus first. You know you are not going to get $100 \%$ support. If you've got $51 \%$ support, you're happy. You move on. You engage with others and eventually get to a point where you fix on a position and it gets through; and it does not end there. You must be accountable. You must be able to prove that it is working, and if it is not working it is your neck on the block. The party wants the assurance that - yes, we support you, but - if this thing explodes, you carry the can. Practically, that is how these decisions are taken, because I would be lying to you if I would say that we are all happy and all behind it. There is not such a thing.' - Councillor

The Social Consultant described in some detail the difficulty of establishing community priorities as follows:

[Paraphrased:] In the IDP processes, communities will come up with a shopping list of what they want. The Council will then have a certain amount of money and will have to cut the list to fit the budget. The choice of projects within the list is generally made by the Council with reference to total funding available together with rules laying down what can be done with funds from different sources. When services or projects are actually delivered, communities often comment that the particular service or project is not their priority, but they will have it anyway otherwise they won't get anything in the next allocation. A second problem is that a politician may visit an area on a tour and make a comment that he would like to see something in particular (e.g. a settlement with the full range of services and amenities). The official then responds to the politi- 
cian's expressed wish, even if the community has asked for different priorities. Again, the community will never refuse the services and amenities, but when they are built, they may be vandalised. Communities then say that the amenities are nice, but they are not an immediate need. Social Consultant

One of the critical requirements in resolving these difficult political trade-offs is for technical professionals to communicate the consequences of particular courses of action. The Senior Manager puts it as follows:

'I think information that you can give to a politician is to show them ... the consequences [of particular courses of action].' - Senior Manager

To do that, in the first instance, requires strong technical skills and experience in understanding and foreseeing the details of different possible events and their consequences:

'... looking at various aspects of risk ... always comes up, and whether you do it ... subconsciously in your mind, you probably do look at risk and things like that every single day of your life... There is a more structured way of looking at risk from the executive ...point of view...That would be identifying risks within your department, ... [with others] ...developing a strategy for programmes to mitigate those types of risk, and then making sure that they do [achieve] them, and [that] there is some form of monitoring.' - Technical Manager

\section{Category\#3: Characteristics and requirements (qualifying all interactions):}

Within Category\#3, there appeared to be 3 main themes:

- Communication, including communication across all interfaces and between all parties; courage/boldness in communicating the consequences of difficult choices

- A team approach, and understanding the whole system, including trust and mutual support of different players; competence of different players

- And the translation of these matters into the working of the bureaucracy, including: exercise of authority, and fear of transgressing authority; slowness to get an interview or decision

Communication at all levels appears to be critical. Between officials in a technical department, an approach was described by the Technical Manager as follows:

'I am a firm believer in the fact that if more people know more, they are empowered to do more things, so I have a management committee meeting every week...[although] one week it is really abridged ....and every second week it would be a more full one, [with] progress [checked] on all of the actions that get listed, to make sure that things happen. [However], ... when a major issue arises that needs to be communicated, it is communicated immediately and that is usually verbal [or] e-mail or a combination. ... If I think something is really important, I will make sure that I see a person face-to-face, phone call, whatever, so that I know that the person has got the message...' - Technical Manager

On the communication between ward councillors and the community, the Social Consultant commented as follows:

[Paraphrased:] Communication of information about a project from the project managers back to the community is usually done through the ward councillors. If it is a large community, then the chain of people communicating this message might be say four people. In a smaller and younger area, one may well have a person from the community sitting in on the meeting between the project managers and ward councillors, so that the message is more direct - i.e. less of a 'broken telephone' problem. - Social Consultant

So good communication is clearly a recurring theme. But more than simply good communication is the need for courage and boldness at all levels in communicating the true consequences of particular courses of action, and in taking difficult decisions. With respect to the decision-making, the Councillor made the following comments:

'Now we need to take a bold political decision...' - Councillor

The Mayor might say: "You know, we are playing with fire and might end up being very unpopular." " - Councillor

With respect to pointing out the consequences of proposed decisions to politicians, the Senior Manager pointed out that there is a danger that an official may be 'too scared' to do this:

'...Politicians aren't stupid, but sometimes they don't know'. And further: 'If [the politicians] are confronted with the right information, and [they engage with it], then they may be a bit less gung-ho.'- Senior Manager

And again, the Technical Consultant gave a specific example where the responsible officials did not explain the full consequences of a proposed decision to the political decision-makers:

"I could not understand why [the officials] when they had the opportunity did not state the truth in terms of what the problem was and what was needed. So you have now launched [government] into saying something which is not achievable..." - Technical Consultant

More than communication, the Councillor went further to suggest that it required a co-ordinated effort as a team to make real progress:

'...the ability to work as a team...is about establishing relationships, about getting out of your own box for your work to be effective, but knowing which boxes have more impact in your life. But you don't wait for them, you go and ask them and in fact you develop protocols that makes it possible for you to do your work.' - Councillor

And together with a team approach, the Councillor further suggested that it required people who understand how the whole system functions:

'...my understanding is that today...yes, you need people who specialise in a particular skill, in this case it could be water and sanitation systems. But you want people who understand in the context of local government how the entire system functions.' - Councillor

This was echoed by the Technical Manager as follows: 'So I think one needs to have a view of the [organisation] as a whole, [particularly] when you are at an ... executive position. It is not just what your department does which is ... important. You must understand how your department impacts on other departments, and impacts on the [organisation] as a whole. ... To me, that type of thing is very important.' - Technical Manager 
The cumbersome nature of the bureaucracy was another recurring theme, and the difficulties posed by detailed decisionmaking being held by the Mayoral Committee:

'...with large municipalities you've got this bureaucracy.

If you have got to have something passed, it has to go through probably the Mayor's office, and considering the size and scope of the [large municipality] that the Mayor is running, he is he is unable to meet to attend to those things, and the issue of time becomes critical...The bigger it gets, the more [bureaucratic] it gets.' - Social Consultant

And again, describing the difficulty of access:

'In order to see a head of department or senior person to get a decision, one could be waiting for two weeks. You might want to have a one-on-one, but the structure of the organisation doesn't allow that. Your immediate supervisor or line manager may have that type of access, but you don't have that sort of access as a project manager on the ground'. - Social Consultant

Interestingly, the view of the Social Consultant was that the problems of the bureaucracy did not differ much between larger (well capacitated) and smaller (less well capacitated) local authorities:

'I have had interactions with local government officials [in one of the poorer provinces of South Africa], but when I [went to one of the richer provinces], I kind of got a shock because you think...in a city they do things differently, but when you get inside... you think ... we are not as different there, because the principles are the same... You know, I thought things would run differently, but to my surprise, they are like your other municipalities, ... so for me, size didn't really matter" - Social Consultant

What the Social Consultant also pointed out was that the various procedures were strict, and that one was not at liberty to bypass them:

[Paraphrased:] If unforeseen circumstances arise on a contract that requires additional budget, officials on the ground may feel that the best option for the sake of continuity is to let the existing contractor continue with an increased budget. However, there may be different views in the Council. Council may prefer to have another contractor doing that, because they want to empower or involve new contractors. Resolving these different views on a contract can cause a lot of delays. Officials on the ground have been fired for breaking the Code of Conduct if they go ahead and increase the budget without approval from Council. Sometimes Council will support increasing the budget, and other times they won't. You don't know which it will be..... Because one is at the project level and one wants the project to succeed, one tries to make a plan to ensure that it succeeds. But with your senior officials or head of department, as much as they want the product, they have got these systems that they need to follow, and they have got to account for their actions if things go wrong. You can't say that your official did something that you were not aware of. You have got to take the rap. - Social Consultant

From this example, it appears that the decision-making authority is being held right at the top of the organisation, with very little delegation to officials lower down.

The bureaucracy appears cumbersome in itself. Nevertheless the situation appears to be exacerbated by the absence (or low representation) from the decision-making sections of the hierarchy of people with technical skills:

'...within that environment that I have described as a department [see Fig.7]... there are two [problems]: The people who know anything about project management are the ones at the lower end [of the hierarchy]. The ones... [at the top end of the hierarchy] don't know anything about this. So they are technically deficient ....and then from a project management point of view, they are again deficient...There is nothing you can do about the technical side of it, but you can resolve a few issues on the project management side.' Technical Consultant

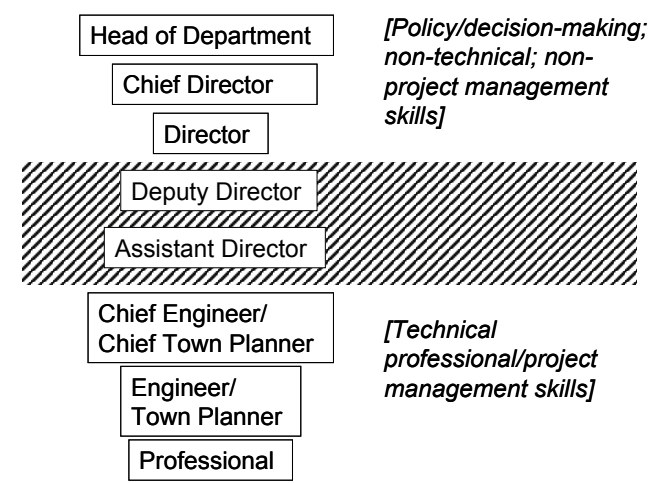

Figure 7

Interface between policy/decision-makers and technical professionals in departmental hierarchy

'So we are sitting now with a person who is not going to believe what is essentially the only expert advice he has got... and he doesn't know how else to go about making that decision, or how to interrogate the information [that he is given]...That tension then on its own creates a longer loop in terms of how the decision is arrived at, because it has got to be vetted and revetted many times. And when that decision is finally made, because that distrust is still not out of the system, the decision that gets made tends to be on the conservative side.' - Technical Consultant

There is also a link between competence and trust. Competence and trust need to go together.

'...I think we are very fortunate in the councillor that we have with [municipal services] because [he] does understand service provision and [the] constraints of it. I think if you had somebody who didn't understand it, it would be quite difficult. On the one hand you can't take [him] for a ride and just tell him anything. On the other hand, [he supports] you if you come up with a good and reasonable answer.' - Technical Manager

Linked to the issue of competence at different levels of the hierarchy, the issue of race was also raised by two of the interviewees - one white and one black. The matter is undoubtedly complex. Nevertheless, both indicated that it was problematic where matters of race overrode matters of experience in allocation of positions of authority.

\section{Conclusions}

- The investigation developed and documented an exploratory methodology based primarily on in-depth interviews 
and a literature review which enabled the collection of evidence and development of a 'first pass' typology of knowledge, context and individual competencies with respect to developmental water services

- With respect to knowledge, the investigation found that while there is a lot of information readily available in the sector on the provision of water services to meet developmental objectives, what appears to be weak or missing is information on how to apply this information in context

- With respect to context, the investigation established a simple preliminary framework which described the combination of political and technical disciplines in a unified approach, and the translation of this into the bureaucracy

- On the evidence of the in-depth interviews, the contextual aspects of developmental water services, described by the above framework - and, in particular, the workings of the bureaucracy - would appear to constitute the major challenge facing high-level technical professionals and decision-makers in the provision and sustainability of water services

- More generally, the investigation established that for effective provision of water services within a developmental context, there is a close relationship between the three components of knowledge, context and individual competencies; and that it is difficult to address any one of the 3 components without reference to the other two.

\section{Acknowledgements}

The information contained in this paper emanates from a project funded by the Water Research Commission of South Africa entitled: Knowledge Uptake by Technical Professionals and Decision-Makers for Developmental Water Services (WRC Project No. K5/1519).

This project simply would not have been possible without the contributions of the 10 or so high-level technical professionals and decision-makers in the water sector, who participated as interviewees in the in-depth interviews or in the abbreviated postal/telephonic surveys. It has been a remarkable 'window' that their participation has opened for us onto that part of the water sector. We have specifically omitted their names - and the names of their organisations - in order to retain confidentiality. That in no way diminishes our thanks to them. We have made every effort to record and utilise their comments truthfully in both word and intention. However, if we have misunderstood or misinterpreted anything, the fault is ours, not theirs.

\section{References}

BENSON IT (2006) The meaning of "Renewal", Centrepoints Newsletter 2. Centre for Cultural Renewal. http://www.culturalrenewal. ca/news/nws2.htm (Accessed July 2006).

CELE N (2006) Masondo picks and chooses. Northcliff Melville Times. 34 (13) (week ending 31 March). 28.

ELDER L and PAUL R (2002) The Miniature Guide to the Art of Asking Essential Questions. The Foundation for Critical Thinking, Dillon Beach, California, USA.

JOHANNESBURG WATER (2005) Minutes of the Meeting of the Board of Johannesburg Water (Pty.) Ltd., 7 September 2005, single item considered (no item number), Johannesburg, South Africa.

NOSICH GM (2001) Learning To Think Things Through: A Guide to Critical Thinking Across the Curriculum. Prentice-Hall, Upper Saddle River, New Jersey, USA.

PHASIWE K (2003) Development Bank worried about backlog. Business Day. Fri 11 July 2003. 3.

VAN RYNEVELD MB and McCUTCHEON RT (1997) Teaching of development engineering at undergraduate level in the civil engineering degree at the University of the Witwatersrand, Johannesburg. Proc. $8^{\text {th }}$ Annual Congress of the South African Institution of Civil Engineering, "Magnum Opus". 17-18 April, Eskom Conference Centre, Midrand, South Africa..

WOOLDRIDGE D and CRANKO P (1997) Transforming public sector institutions. In: Fitzgerald P, McLennan A and Munslow B (eds.) Managing Sustainable Development in South Africa. Oxford University Press.

WRC (2002) Knowledge Review 2001/2002. WRC. 